\title{
KEEFEKTIFAN FOCUS GROUP DISCUSSION UNTUK MENINGKATKAN MORAL JUDGMENT MAHASISWA TERHADAP PRILAKU MENCONTEK DI PRODI PSIKOLOGI PENDIDIKAN DANBIMBINGAN FIP UNIMED TAHUN AJARAN 2017/2018
}

\author{
Albert Pauli Sirait ${ }^{1}$, Rahmulyani2, La Hanu ${ }^{3}$ \\ Program Studi Bimbingan dan Konseling, Universitas Negeri Medan ${ }^{1,2}$ \\ Fakultas Ekonomi, Universitas Negeri Medan ${ }^{3}$ \\ Email: \{albertpaulis@gmail.com $\}^{1}$
}

\begin{abstract}
Abstrak
Penelitian ini bertujuan untuk mengetahui keefektifanfocus group discussion untuk meningkatkan moral judgment mahasiswa yang mencontek. Sampel dalam penelitian ini adalah 10 orangdilakukan mengunakan purposive sampling.Teknik pengumpulan data menggunakan angket, dan dianalisis dengan menggunkan uji Wilcoxon.Uji hipotesis menggunakan uji $\mathrm{Z}$ dan diperoleh jumlah $Z_{\text {Tabel }}>Z_{\text {Hitung }}=-1,96>$ 2,805 , dengan standar deviasi pada pre-test $=6,34$ dan pada post- test $=3,6$. Dari data statistik tersebut maka disimpulkan Ha diterima yang artinya terdapat pengaruh signifikan penerapan Focus Group Discussion terhadap peningkatan Moral Judgement Mahasiswa terhadap Prilaku Menyontek di Prodi Bimbingan dan Konseling Unimed T.A 2017/2018.
\end{abstract}

Kata kunci : Moral Judgement, Focused Group Discussion, Menyontek.

\section{PENDAHULUAN}

Orientasi belajar mahasiswa di universitas hanya untuk memperoleh nilai yang tinggi, lebih banyak menggunakan kemampuan kognitif daripada afektif dan psikomotor (Irawati, 2008). Semakin tinggi nilai yang diperoleh mahasiswa, maka mahasiswa itu akan dianggap telah berhasil menguasai materi yang diberikan dosen. Begitu juga akan terjadi sebaliknya jika mahasiswa memperoleh nilai yang rendah. Hal ini memicu mahasiswa berlomba- lomba untuk memperoleh nilai yang tinggi agar dianggap berhasil.

Kemungkinan mengalami kegagalan diangggap sebagai ancaman dan merupakan stimulus yang tidak menyenangkan. Ada berbagairespon yang dilakukan mahasiswa dalam menghadapi ancaman kegagalan, misalnya mempelajari materi secara teratur atau mengerjakan soal-soal latihan yang diberikan dosen.

Ada pula mahasiswa yang memberikan respon menghindari ancaman kegagalan dengan mencontek (Setyani, 2007:2). Mencontek adalah salah satu gejala yang mencemaskan diantara mahasiswa dalam dekade belakangan ini (Michele Borba, 2008). Setiap mahasiswa memiliki perbedaan sikap dan penilaian terhadap perilaku mencontek yang dipengaruhi oleh keyakinan mahasiswa. Banyak mahasiswa beranggapan mencontek sebagai masalah yang biasa 
saja, namun ada juga yang memandang serius masalah ini.

Mencontek bukan cara yang benar untuk memperoleh nilai tinggi.Mencontek akan menimbulkan kekaburan dalam pengukuran kemampuan mahasiswa, dosen menjadi sulit untuk menentukan penilaian secara objektif. Nilai yang diperoleh tidak dapat membedakan antara mahasiswa yang memperoleh nilai tinggi karena kemampuan dan penguasaan terhadap materi pelajaran dengan mahasiswa yang memperoleh nilai tinggi karena mencontek.

Kenyataan menunjukkan bahwa mencontek meningkat di kalangan mahasiswa. Kekhawatiran yang utama adalah semakin banyakmahasiswa yang tampak tidakmerasa bersalah dan menyesal.Sanksi yang diberikan pihak universitas selama ini hanya sebatas teguran verbal, mengambil soal ujian, dan mengurangi nilai dari hasilujian. Jika tidak ada sanksi yang tegas maka mahasiswa cenderung akan mengulanginya. Hal ini merugikan mahasiswa yang rajin belajarkarena objektifitas penilaian tidak ada sama sekali, yang dilihat hasil ujian bukan keseluruhan proses dalam pembelajaran.

Adapun yang dimaksud dengan menyontek atau cheating adalah perbuatan yang menggunakan cara- cara yang tidak sah / terhormat dalam medapatkan keberhasilan akademis atau menghindari kegagalan akademis (Bower dalam M. Taufiq \& Yuli Azmi, 2015: 1). Menurut Pincus \& Schemelkin (dalam Kiki Nurmayasari \&Hadjam Murusdi, 2015: 3) perilaku menyontek merupakan suatu tindakan curang yang sengaja dilakukan ketika seseorang mencari dan membutuhkan adanya pengakuan atas hasil belajarnya dari orang lain meskipun dengan cara yang tidak sah seperti memalsukan informasi terutama ketika dilaksanakannya evaluasi akademik. Kemudian menurut Mudrikah menyontek merupakan mencuri hasil karya, jerihpayah orang lain secara diam - diam ataupun terang-terangan (Samiroh \&Zidni Immawan dalam JurnalPsikologi Islami Vol. 1 No.2, 2015:3).

Nadhirah (dalam Samiroh \&Zidni Immawan, 2015: 6-7)mengatakan alas an yang menyebabkan mahasiswa menyotek, yaitu berasal dari faktor internal dan faktor eksternal (dalam diri individu dan dari luar individu). Faktor Internal, meliputi: Pertama, konsep diri. Kedua, self-efficacy. Ketiga, inteligensi. Keempat, kecemasan atau ketegangan yang dialami Kelima, gender. Faktor Eksternal, maliputi: Pertama, Kelompok sebaya. Kedua, tekanan untuk mendapatkan nilai dan peringkat tinggi. 
Ketiga, pengawasan selama ujian/ tes, pengawasan yang tidak ketat. Keempat, jenis materi yang diujikan.

Setiap orang berpotensi untuk mencontek dan kecenderungan mencontek semakin meningkat di dunia pendidikan Indonesia. Perilaku mencontek sebagai bagian dari masalah moral, maka perlu segera dilakukan intervensi untuk meningkatkan penalaran moralmahasiswa yang mencontek.

\section{KAJIANPUSTAKA}

Mencontek adalah tindakankoruptif yang mengacu kepada kebohongan akademik. Mencontek berasal dari kata sontek, artinya mencontoh, meniru, atau mengutip tulisan orang lain sebagaimana aslinya (Kamus Besar Bahasa Indonesia, 2002:1084). Bower (Irawati, 2008) mendefinisikan mencontek sebagai perbuatan yang menggunakan cara-cara yang tidak sah untuk tujuan yang sah atau terhormat yaitu mendapatkan keberhasilan akademis atau menghindari kegagalan akademis. Menurut Deighton, mencontek adalah upaya yang dilakukan seseorang untuk mendapatkan keberhasilan dengan cara-cara yang tidak jujur (unfair).

Mencontek adalah suatu wujud perilaku dan ekspresi mental seseorang yang merupakan hasil belajar dari interaksi dengan lingkungannya. Cizek
(Garavalia, et al., 2007) memberikan definisi mencontek yang tidak terlalu membatasi.

Menurut Cizek mencontek terbagi dalam tiga kategori: (1) memberi, mengambil, atau menerima informasi; (2) menggunakan peralatan yang dilarang saat ujian; dan (3) memanfaatkan kelemahan orang lain, prosedur, atau proses untuk memperoleh keuntungan pada saat ujian untuk hasil akademis.

Alhadza (Tn, 2004)

mendefinisikan mencontek sebagai perbuatan atau trik-trik yang tidak jujur, perilaku tidak terpuji atau perbuatan curang yang dilakukan oleh seseorang untuk mencapai keberhasilan dalam menyelesaikan tugas-tugas akademik terutama yang terkait dengan evaluasi atau ujian hasil belajar.

Moral judgment akan digunakan pada saat seseorang menghadapi dilema moral. Ia harus memutuskan tindakan yang akan dimunculkannya. Dilema moral juga akan terjadi pada para mahasiswa yang menghadapi ujian dan akan memutuskan untuk mencontek atau tidak mencontek. Hal ini terjadi karena disatu sisi mahasiswa dituntut untuk jujur dalam mengerjakan soal- soal yang diberikan karena ujian tersebut bertujuan untuk mengevaluasi kegiatan belajar 
mengajar yang telah dilakukan, disisilain mahasiswa ingin mendapat nilai tinggi agar lulus ujian dan mahasiswa mengetahui bahwa mencontek bukan tindakan yang boleh untuk dilakukan di dalam situasi ujian.

\section{Kohlberg}

(1984:196-197)

berpegang pada teori perkembangan kognitif. Berkaitan dengan pendekatan tersebut, Kohlberg mengajukan beberapa asumsi yang melandasi pemikiran mengenai perkembangan moral sebagai berikut: (1) perkembangan moral berdasarkan pada struktur kognitif atau komponen penalaran moral; (2) motivasi dasar moralitas lebih sebagai upaya untuk mendapatkan penerimaan, rasa kompeten, harga diri, atau kemampuan mengatur diri daripada sekedar untuk kebutuhan- kebutuhan biologis atau pengurangan ketakutan; (3) aspek utama dari perkembangan moral bersifat universal karena semua kebudayaan mempunyai sumber yang sama untuk terjadinya interaksi sosial, alih peran dan konflik sosial yang sama, yang memerlukan integrasi moral; (4) pertumbuhan dasar dan prinsip moral lebih melalui pengalaman- pengalaman selama interaksi sosial daripada melalui penanaman aturan- aturan dari luar, tahap moral tidakdirumuskan atas dasar aturanaturan yang diinternalisasikan, tetapi atas dasar struktur interaksi antara "diri" dan "orang lain" dalam lingkungan sosial; dan (5) pengaruh lingkungan terhadap perkembangan moral tergantung seberapa jauh stimulusi kognisi dan sosial sesuai dengan tahap perkembangan anak dan bukan karena adanya pengalaman khusus, seperti penggunaan disiplin orang tua, atau pemberian hadiah atau hukuman.

\section{METODE PENELITIAN}

Jenis penelitian yang digunakan oleh peneliti ini adalah penelitian eksperimen semu dengan pendekatan kuantitatif yaitu suatu tindakan yang dirancang untuk menyelidiki dengan prosedur ilmiah, menggunakan metode tertentu, untuk memperoleh jawaban atas pertanyaan penelitian melalui data yang dikumpulkan (Menanti, 2010:28).

Desain yang digunakan dalam penelitian ini adalah one group pre-test post-test design yaitu dengan melakukan tes sebelum eksperimen (O1) dan melakukan tes sesudah eksperimen (O2). Adapun polanya sebagai berikut:

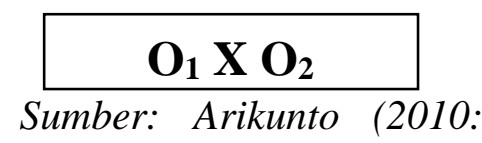

124)

Sampel penelitian ini adalah mahasiswa BK Reguler A 2016 yang berjumlah 10 orang mahasiswa. Pengisian angket yang sudah diujisecara valid atau sahih yang berjumlah 50 item disebarkan ke 
mahasiswa BK Reguler B 2015 yang berjumlah 26 mahasiswa untuk mengambil sampel yaitu sebanyak 10 orang yang memiliki kebiasaan menyontek tertinggi.

Pengumpulan data dilakukan melalui angket yang disusun sendiri oleh peneliti berdasarkan pada aspek dengan pernyataan tertulis yang digunakan untuk memperoleh data dari responden mengenai perilaku bullying verbal dengan mengacu pada skala likert.Uji validitas dilakukan untuk menentukan angket dengan menggunakan skor setiap butir dengan menggunakan skor total yang merupakan jumlah tiap skor butir. Untuk menguji validitas ini dilakukan dengan menggunakan teknik analisa data dan koefisien product moment.

Teknik analisis data dalam penelitian ini dilakukan dengan menggunakan analisis data statistik non parametrik atau dengan menggunakan uji Wilcoxon (dalam Sudjana 2005:450). Penelitian ini dilakukan di jurusan Bimbingan dan Konseling, Fakultas Ilmu Pendidikan,Universitas Negeri Medan.

\section{HASIL PENELITIAN DAN PEMBAHASAN}

Pelaksanaan uji coba instrumen angket kebiasaan menyontekmahasiswa di jurusan PPB FIP UNIMED dilaksanakan terhadap 30 orang siswa diluar sampel.
Dalam tahap uji coba ini peneliti meminta kesediaan 30 orang mahasiswa tersebut untuk mengisi angket yang diberikan berdasarkan keadaan moral judgement mahasiswa yang sebenarnya, jujur dan terbuka. Sebab dalam angket tersebut tidak ada jawaban benar ataupun salah.

Setelah angket terkumpul, selanjutnya dilakukan penelitian terhadap angket dengan cara membuat format nilai berdasarkan skor-skor yang ada pada setiap angketnya. Kemudian skor yang merupakan pilihan subjek pada setiapbutir angket ditabulasi dan diolah secara manual.

Uji coba angket befungsi untuk mengetahui apakah instrumen tersebut layak digunakan untuk memperoleh data tentang kebiasaan menyontek mahasiswa dengan menggunakan rumus Product Moment. Berdasarkan hasil perhitungan koefisien korelasi, untuk butir nomor 1 $\mathrm{r}_{\text {hitung }}=0,406$ pada taraf signifikan $\alpha=$ $5 \%$ dan $\mathrm{N}=30$ didapati nilai $\mathrm{r}_{\text {tabel }} 0,361$ selanjutnya hasil tersebut dapat dilihat bahwa bahwa rhitung lebih tinggi dari rtabel yaitu $0,653>0,361$ sehingga dapat disimpulkan bahwa butir angket nomor 1 dinyatakan valid, selanjutnya dari 81 butir angket yang diuji cobakan kepada 30 mahasiswa diperoleh 50 butir angket yang valid (dapat digunakan dalam pengumpulan data), sedangkan 31 butir 
angket dinyatakan Tidak Valid.

Untuk uji reliabilitas angket, berdasarkan hasil perhitungan dengan menggunakan rumus Alpha, diketahui $\mathrm{r}_{11}$ $=0,924$. Diketahui bahwa nilai $\mathrm{r}_{11}(0,924)$ $>\mathrm{r}_{\text {tabel }}(0,361)$ maka variabel ini adalah reliabel. Setelah dibandingkan dengan indeks korelasi termasuk dalam kategori cukup tinggi. Dengan demikian dapat disimpulkan bahwa angket kebiasaan menyontek mahasiswa telah memenuhi kriteria reliabilitas sehingga dapat digunakan sebagai alat pengumpul data.

Hasil pre-test, diketahui 6 orang mahasiswa moral judgement kebiasaan menyontekkategori rendah, 4 orang mahasiswa dalam kategori sedang. Hasil perolehan skor pada pre-test tersebut tertinggi 116, skor terendah 86. Rata-rata (M) skor $=99,1$ dan standar deviasi (SD) $=20$.

Hasil post-test diketahui bahwa seluruh sampel berada dalam kategori Moral Judgement Kebiasaan Menyontek dalam kategori tinggi. Hasil perolehan skor pada post-test tersebut tertinggi 197 skor terendah 186. Rata-rata $(\mathrm{M})$ skor $=$ 192,4 dan standar deviasi $(\mathrm{SD})=3,6$

Bentuk perbandingan Moral judgement menyontek mahasiswa sebelum dan sesudah diberi layanan bimbingan kelompok teknik FGD dapat juga dilihat secara nyata pada Gambar 1 berikut ini.

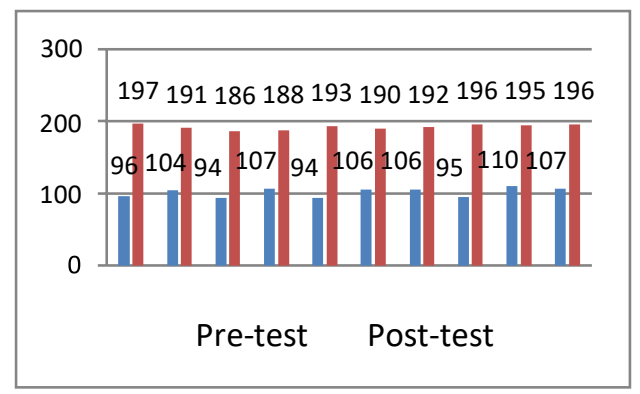

Gambar 1 Grafik Perbandingan Hasil pre-test dan post-test

Pengujian hipotesis dilakukan dengan perhitungan uji jenjang bertanda wilcoxon. Pada uji jumlah jenjang wilcoxon diperoleh hasil perhitungan jumlah jenjang bertanda positif $=55,5$ dan jumlah jenjang bertanda negatif $=0$. Jadi, nilai $\mathrm{J}=0$ yaitu jumlah jenjang yang lebih kecil.Adapun persamaannya adalah untuklandasan pengujian dipergunakan nilai $\mathrm{Z}$.

$\mathrm{H}_{0}$ ditolak pabila $\mathrm{Z}_{\text {tabel }}>\mathrm{Z}_{\text {hitung. }}$ Karena nilai $Z_{\text {tabel }}$ yaitu $-1,96$ dan itu lebih besar dari nilaiZ $Z_{\text {hitung }}$ adalah $-2,805$.

Dengan demikian $\mathrm{H}_{\mathrm{a}}$ diterima yang artinya terdapat pengaruh signifikan tingkat moral judgement mahasiswa dalam menyontek sebelum dan sesudah diberi perlakuan. Dengan kata lain Layanan bimbingan kelompok teknik FGD memberikan efek yang signifikan terhadap moral judment mahasiswa dalam menyontek.

\section{PENUTUP}

\section{Kesimpulan}

Berdasarkan hasil penelitian dapat disimpulkan bahwa ada pengaruh penerapan layanan bimbingan kelompok teknik Problem Solving terhadap disiplin 
belajar siswa, hal ini di ketahui dari hasil pre-test disiplin belajar siswa diperoleh rata-rata $(\mathrm{M})=99,1$ dan standar deviasi $(\mathrm{SD})=20$ sedangkan post-test diperoleh rata-rata $(M)=192,4$ dan standar deviasi $(\mathrm{SD})=3,6$ dan hasil perhitungan uji hipotesis diperoleh $\mathrm{Z}_{\text {tabel }}$ yaitu -1,96 dan itu lebih besar dari nilai $Z_{\text {hitung adalah - }}$ 2,805, maka $\mathrm{H}_{0}$ ditolak dan Ha diterima dan dengan kata lain terdapat pengaruh signifikan layanan bimbingan kelompok teknik Focus Group Discussion terhadap moral adjudgement mahasiswa terhadap prilaku menyontek.

\section{DAFTAR PUSTAKA}

Devi Kusrieni. 2014. Hubungan Efikasi Diri Dengan Perilaku Mencontek. Psikopedagogia 2014 Universitas Ahmad Dahlan. II(3): 103-105).

Ginanjar Mukti Priaswandy. 2015. Hubungan Antara Self Efficacy Dengan Perilaku Menyontek Pada Siswa Kelas Xi Di Sma Negeri 1 Pleret Bantul Yogyakarta. Jurnal Bimbingan dan Konseling. IV(6): 2).

Hamdani, Rusydan Ubaidi. 2014. Menyontek...?Yukk!!Hmm...n ggak ah!!. Jakarta : TRANSMEDIA PUSTAKA.

Junierissa Marpaung. 2016.Counseling Behavoir Rational Approach Therapy inReducing Stress.
JurnalKOPASTA, , III (1): 24-25). Kiki Nurmayasari, dan Hadjam Murusdi. 2015. Hubungan Antara Berpikir Positif Dan Perilaku Menyontek PadaSiswa Kelas X Smk Koperasi Yogyakarta. Jurnal Fakultas Psikologi. I (3).

Menanti, Asih. 2013. Penelitian Eksperimen. Medan : Penerbit Universitas Negeri Medan.

M. Edi Kurnanto. 2013. Konseling Kelompok. Bandung : ALFA BETA.

M. Taufiq Hidayat. Hubungan Antara Self Efficacy Dengan Perilaku Menyontek Saat Ujian Pada Mahasiswa Universitas Esa Unggul. Fakultas Psikolog

iUniversitas Esa Unggul.

Mungin Wibowo. 2005. Konseling Perkembangan. UNES.

Namora Lumongga. 2011. Memahami Dasar - dasar Konseling Dalam Teori dan Praktek. Jakarta : KEBCANA PERDANA MEDIA GRUP.

Neni Noviza. 2013. Metode Bibliotherapy Pada Kisah Nabi Yusuf AsSebagai Media Konseling Rasional Emotif. Warda. XXVI.

Nur Tanjung, Bahdin. 2012. Pedoman Penelitian Karya Ilmiah. Jakarta : Kencana.

Prayitno. 1995. Layanan Bimbingan dan Konseling Kelompok (Dasar dan Profil). Jakarta :Ghalia Indonesia. 